\title{
Defining low-dose corticosteroid: the pendulum still oscillates
}

To the Editor:

TAGAMI et al. [1], in their retrospective analysis, have contributed to further understanding of the use of corticosteroids in severe community-acquired pneumonia (CAP) and put forth an inference on the current dispute. Some issues, however, need further discussion.

The patients with severe CAP and sepsis may have adrenal insufficiency. In this retrospective analysis, neither the cortisol level at baseline nor the response to corticotrophin testing has been mentioned, to assess for possible adrenal insufficiency. Therefore, the role of corticosteroids in management of severe CAP should be based on the assessment for adrenal reserve before drawing any conclusions.

The dosage of low-dose corticosteroid used in this study [1] is intravenous infusion of methylprednisolone $0.5-2.5 \mathrm{mg} \cdot \mathrm{kg}^{-1} \cdot \mathrm{day}^{-1}$ (an equivalent dose of hydrocortisone is $2.5-12.5 \mathrm{mg} \cdot \mathrm{kg}^{-1} \cdot \mathrm{day}^{-1}$ ). Therefore, an average person weighing $60 \mathrm{~kg}$ would require up to $750 \mathrm{mg}$ hydrocortisone. However, according to the sepsis guidelines, $200-300 \mathrm{mg} \cdot$ day $^{-1}$ of hydrocortisone is considered a low-dose steroid, which is indicated in patients with septic shock [2].

Patients with comorbidities like asthma or chronic obstructive pulmonary disease are more likely to benefit with systemic corticosteroids. It is unclear if there was any indication bias with patients having any acute associated condition requiring corticosteroids [3].

$@$ ERSpublications

Defining low-dose corticosteroid in severe community-acquired pneumonia http://ow.ly/OazzW

Prasanta Raghab Mohapatra ${ }^{1}$, Gourahari Pradhan ${ }^{1}$, Priyadarshini Behera ${ }^{1}$, Sourin Bhuniya ${ }^{1}$, Manoj Kumar Panigrahi ${ }^{1}$ and Deepak Aggarwal ${ }^{2}$

${ }^{1}$ Dept of Pulmonary Medicine, All India Institute of Medical Sciences, Bhubaneswar, India. ${ }^{2}$ Government Medical College and Hospital, Chandigarh, India.

Correspondence: Prasanta Raghab Mohapatra, Dept of Pulmonary Medicine, All India Institute of Medical Sciences, Bhubaneswar 751019, India. E-mail: prmohapatra@hotmail.com

Received: Feb 102015 | Accepted: Feb 222015

Conflict of interest: None declared.

\section{References}

1 Tagami T, Matsui H, Horiguchi $\mathrm{H}$, et al. Low-dose corticosteroid use and mortality in severe community-acquired pneumonia patients. Eur Respir J 2015; 45: 463-472.

2 Dellinger RP, Levy MM, Rhodes A, et al. Surviving Sepsis Campaign: international guidelines for management of severe sepsis and septic shock: 2012. Crit Care Med 2013; 41: 580-637.

3 Fernández-Serrano S, Dorca J, Garcia-Vidal C, et al. Effect of corticosteroids on the clinical course of community-acquired pneumonia: a randomized controlled trial. Crit Care 2011; 15: R96.

From the authors:

We would like to thank P.R. Mohapatra and colleagues for their comments and interest in our study [1]. We also appreciate the editors of the European Respiratory Journal for giving us the opportunity to reply. The points made by P.R. Mohapatra and colleagues regard the following: 1) the corticotrophin test, 2) the dosage of corticosteroid, and 3) comorbidities as confounding factors for the use of corticosteroid.

We agree that some patients with community-acquired pneumonia (CAP) in the present study [1] might have had adrenal insufficiency. However, we possessed no data on how many patients were responders or 